A revised and updated version of this working paper has been published by Taylor \& Francis in EASTERN EUROPEAN ECONOMICS. Please use the journal version only! 


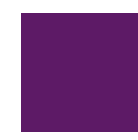

\section{Lodz}

Economics

Working

Papers

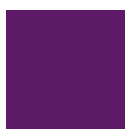

SOURCES OF REgIONAL INFLATION IN POLAND

Paweł Gajewski 


\title{
Sources of Regional Inflation in Poland
}

\author{
Paweł Gajewski ${ }^{1}$
}

\begin{abstract}
This paper aims at shedding some light on the sources of regional inflation in Poland. More specifically, it investigates the role of external, national and idiosyncratic shocks. In a two-step procedure, we estimate orthogonal components corresponding to each of these shocks, while performing variance decomposition to assess their relative importance in explaining inflation in individual regions. In the course of the paper we develop two ad hoc hypotheses. First, that regional inflation rates are largely driven by national shocks, while the impact of external shocks is smaller. Second, that shocks to inflation which are asymmetric between Poland and its external environment contribute to the cross-regional divergence of inflation rates in Poland. Empirical evidence supports both of these assertions. Indeed, we show that the importance of idiosyncratic shocks in the Polish regions is strikingly low. However, regional differences in inflation co-movements can be attributed to the diverse importance of global and national shocks. In auxiliary regressions we confirm that shocks which strongly and asymmetrically affect inflation in Poland and the EU, also contribute to crossregional inflation divergence in Poland. To the best of our knowledge this is the first attempt to investigate sources of regional inflation in a CEE country.
\end{abstract}

Keywords: regional inflation, principal components, parallel analysis, regional economic dynamics

JEL codes: E31, R11

\footnotetext{
${ }^{1}$ Department of Economics, Faculty of Economics and Sociology, University of Lodz, Lodz, Poland (pawelg@uni.lodz.pl). This work was supported by the Polish National Science Center under grant number DEC-2014/15/B/HS4/01996.
} 


\section{Introduction}

The case for understanding cross-regional inflation patterns is important for several reasons. First, it provides monetary policymakers with important knowledge on background mechanisms driving aggregate inflation. Second, as Yilmazkuday (2013) points out, if differences in inflation across regions are persistent, output growth in relatively low-inflation regions can be suppressed due to a higher real interest rate in the presence of common monetary policy. Consequently, inflationary pressure can keep falling in low inflation regions and rising in high-inflation regions due to this feedback loop. Regional inflation divergence can thus be a self-reinforcing mechanism with an impact on regional development processes that policymakers might be interested in monitoring and shaping. Finally, if inflation differentials are due to discrepancies in price stickiness, then regions with stickier prices bear a disproportionally large share of the adjustment after a monetary shock. Benigno (2004) suggests that central banks should overweigh regions with higher nominal rigidity and underweigh more flexible regions to avoid excessive total welfare loss.

There are basically two reasons why inflation can differ across regions within a country; both of these are related to region-specific structural features. First, local labour market conditions and business sector peculiarities can uniquely influence regional inflationary pressure. ${ }^{2}$ Second, regions can respond asymmetrically to global and national shocks. Economic structures, geographical location and trade patterns can make regional inflation more or less responsive to global commodity price developments, the economic environment in neighbouring countries or in the country of origin. Consequently, the regional inflation rate is a product of various global, national and local shocks with associated unique weights on each of them. We believe that it is particularly important to be aware of how regional inflation is influenced by a mixture of global, national and idiosyncratic shocks. For a country like Poland, a non-EMU EU member state, it is important in addition to be able to understand how this composition might change with possible future EMU accession.

This paper aims to shed some light on sources of regional inflation in Poland. More specifically, it investigates the role of external, national and idiosyncratic shocks in driving inflation across Polish regions. To the best of our knowledge this is the first attempt to investigate sources of regional inflation in a CEE country.

\footnotetext{
${ }^{2}$ Gajewski (2015) shows how Phillips curves differ across Polish regions.
} 
Our empirical strategy generally follows Forni and Reichlin (2001), Stock and Watson (2002) and Beck et al. (2009). In a two-step procedure, we estimate orthogonal principal components corresponding to the three sets of shocks. Variance decomposition is then performed to assess the relative importance of the shocks in explaining inflation in individual regions. A similar approach is also adopted by Krusper (2012), who analyses sources of Hungarian (aggregate) inflation.

\section{Literature review on regional inflation}

Our research problem fits in the larger discussion on "global inflation", i.e. the hypothesis that a tendency of global dynamics has gradually started to dominate inflation movements within countries and regions around the world, at least in its developed regions. Empirical support to this hypothesis is indeed growing. Eickmeier and Moll (2010), Cicarelli and Mojon (2010) and Mumtaz and Surico (2012) all provide evidence that such common dynamics have developed in recent years or decades. According to Cicarelli and Mojon (2010) for example, global factors are responsible for as much as $70 \%$ of inflation variance in developed countries.

Mumtaz and Surico (2012) associate the recent rise of global inflation with the moderation period before 2008. A major role of common (supranational) factors is also to be found in previous studies devoted to inflation in CEE countries. Indeed, Stavrev (2009), Krusper (2012) and Hałka and Szafrański (2015) all employ some kind of a factor model and reach similar conclusions in this respect. However, the strong dependency of country inflation rates on global factors is by no means a unanimous conclusion. Monacelli and Sala (2009) investigate dynamics of inflation indices disaggregated by sectors in United States, Germany, France and the United Kingdom to find the common international factor explaining between $15 \%$ and $30 \%$ of the variance of consumer prices. While they claim that this range is the lower bound for the contribution of international factors to inflation dynamics, it is still substantially less than in Mumtaz and Surico's (2012) paper.

The body of previous research on within-country regional inflation, while emerging, is still modest. What is understandable is that the problem has mostly been given attention in countries that are spatially heterogeneous with respect to their economic structures, being that this is what makes them relatively prone to diversified inflation patterns. For instance, Alberola and Marques (1999) investigate regional inflation in Spain between 1962 and 1993. They find the differences to be rather small but persistent in nature. 
Moreover, a strong common (national) dynamics is revealed to be a factor driving regional series. These findings are generally confirmed in a recent paper of Garcia-Cintado et al. (2015). Using the PANIC approach of Bai and $\mathrm{Ng}$ (2004), the paper finds evidence of a common stochastic trend, which drives regional inflation rates and adds substantial persistence to their movements.

Italy is another relatively big country with even more profound cross-regional differences. Vaona and Ascari (2012) investigate the persistence of inflation across Italian regions and seek factors to explain its degree. They find the most important factors to be economic backwardness and the low intensity of competitiveness in the retail sector. In another interesting paper, Nagayasu (2011) provides evidence of significant discrepancies in regional inflation rates among Japanese prefectures and also finds significant differences in responses to common shocks, suggesting that inflation differentials are related to the diverse vulnerability of regional economies to external and national shocks.

The research closest to our paper is the study of Beck et al. (2009), which adopts regional perspective in a panel of selected EU member states to investigate the sources of shocks driving inflation across countries and regions within a dynamic factor model framework. They find that EMU-wide shocks are the most important drivers of regional inflation in EMU, but some important differences exist across countries. Quite different conclusions are drawn by Marques et al. (2014), who investigate the geographical sources of inflation in regions of Chile. They demonstrate that common macroeconomic factors explain a small proportion of the variability of disaggregated commodity inflation series, while local conditions appear more relevant in such cases.

\section{Statistical data}

Regional inflation in a country like Poland - a European medium-sized economy with a flexible exchange rate regime - should largely be explained by national shocks related to a common monetary policy, common exchange rate fluctuations affecting import and export prices, and country-specific demand developments. At the same time, the relatively deep integration with the EU should be reflected in the non-negligible impact of global shocks. These not only include the macroeconomic environment there, but also oil and other commodity price fluctuations in global markets, external sentiment developments (e.g. global risk appetite) and many other possible factors. However, some regional inflation drivers 
remain and are related to local labour market conditions, local economic structures, openness, etc. (see: Beck et al., 2009). In this paper we assume that all the national and external influences on regional inflation come via inflation in the respective areas (i.e. Poland and external countries).

We use quarterly NUTS-2 regional inflation rates spanning from 2001Q4 to 2015Q2 as well as aggregate quarterly series for all the EU28 countries, US, Norway and Iceland in the same period. The latter group forms an external inflation environment for the Polish regions in our empirical exercise. The sources of data are the Polish Central Statistical Office (GUS) and the Eurostat, respectively. Table A1 shows descriptive statistics of inflation data in both these datasets.

Let us turn to inspecting regional inflation in Poland. As expected, the differences between mean inflation rates across the regions are low and do not exceed 0.44 percentage points. This notwithstanding, we have performed an F-test for equality of means in the sample and the null hypothesis was strongly rejected. Inflation was most volatile in Zachodniopomorskie (northwest Poland) and most stable in Opolskie (located in the southern part of the country). , However, simple data examination does not generally allow conclusions to be drawn on geographical patterns regarding the mean inflation rate or its volatility. The relationship between the mean and standard deviation, while positive is also rather weak.

Correlation coefficients between regional inflation rates are all very high, as expected (Table A2). They range from between 0.94 and 0.99 and are similar as e.g. in Japan (after eliminating one outlier, Nagayasu, 2011). Indeed, only two pairs of regions with coefficients lower than 0.95 can be identified. The first pair is composed of regions located on opposite sides of the country: Pomorskie (north) - Śląskie (south), while the second one consists of Mazowieckie (with the capital city Warsaw, dominated by business services) and Warmińsko-mazurskie (north-eastern region with traditionally highest unemployment rate and relatively low incomes). Altogether, tight co-movements and unequal mean inflation rates can be jointly interpreted as a suggestion of weak idiosyncratic components and highly persistent differences. We can now compare aggregate and regional inflation in Poland with its developments in EU, being a natural source of external shocks.

Figure 1 shows that inflation in Poland was more volatile than in the EU, at least until early 2008. When the financial and economic crisis struck in the second half of 2008, inflation in 
the EU went down quickly, but Polish aggregate inflation did not follow as the decline was more muted here. What happened, however, was an increase in the min-max range across regional inflation rates. This range remained elevated (by historical means) until about mid2011, when the EU and Polish inflation rate came closer together again.

Figure 1. Inflation rate in Poland an EU

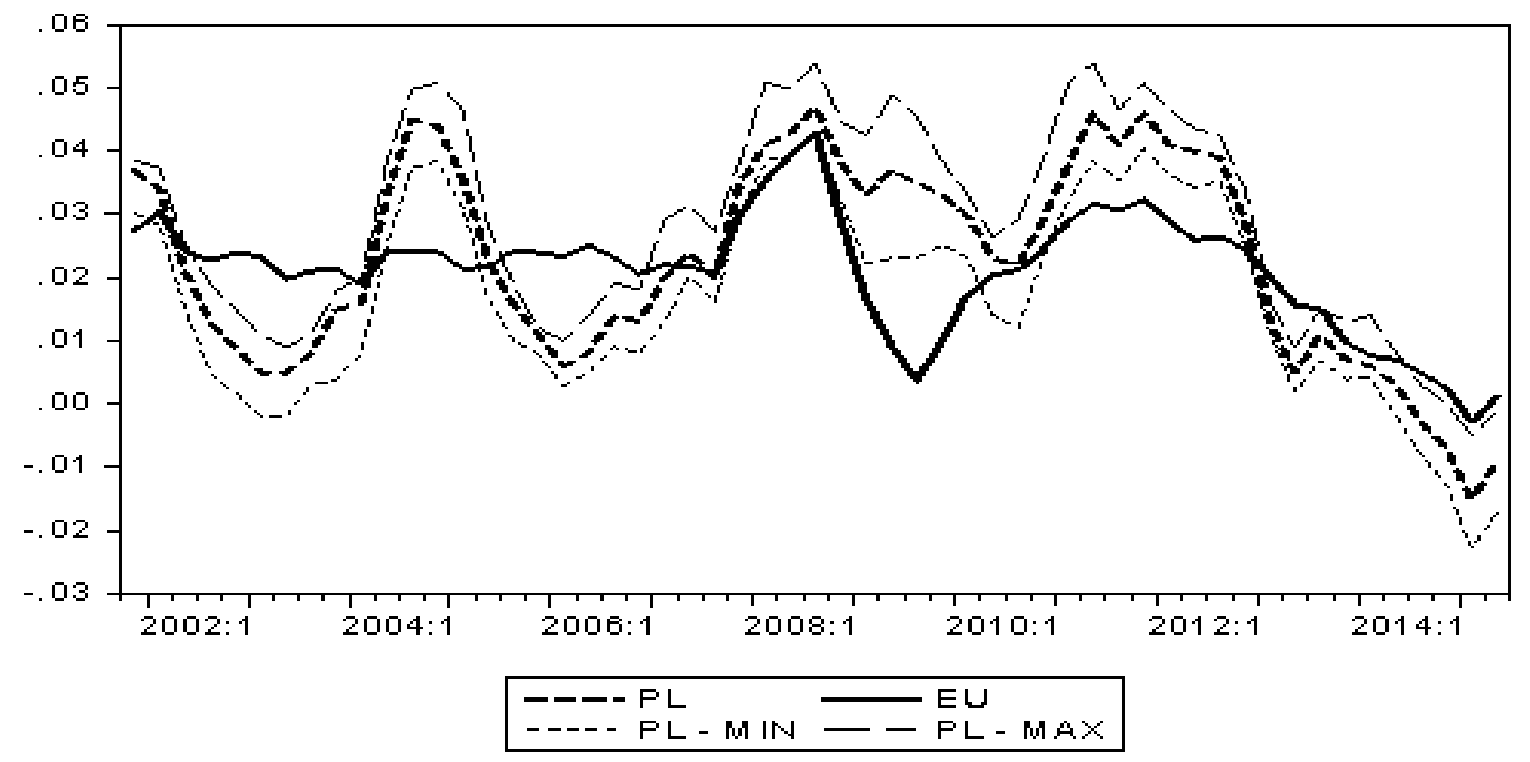

Overall, two preliminary observations can be made in Figure 1. First, inflation rates across regions were fairly closely clustered around Polish aggregate inflation, while the link between the latter and EU average inflation was rather weak. Despite the strong link between GDP fluctuations in Poland and EU (see, for example, Krajewski et al., 2015) this is hardly surprising, given the free floating exchange rate regime in Poland and its presumable external shock-absorbing role (see: Dąbrowski and Wróblewska, 2015). Second, stronger deviations between Polish and EU inflation have coincided with wider min-max ranges, suggesting an asymmetric impact of EU inflation on Polish regions. To summarise, the data inspection performed in this section lead us to formulate the first ad hoc hypothesis, which will be verified empirically in the next sections.

$\mathrm{H}_{1}$ : Regional inflation rates are largely driven by national shocks, while the impact of external shocks is smaller. 
Prior to performing any empirical exercise that involves the use of time series methods, the stationarity issue in our databases needs to be addressed. That being said, testing for unit root in inflation series is a difficult task, especially when the short sample problem exists, as in our case. In most papers, the usually applied ADF, Phillips-Perron and KPSS tests, which are known to suffer from the very low power, produce conflicting results and the authors having to resort to visual inspection of the data (see for example: Beck, et al, 2009, Chang et al, 2013, Forster and Tillman, 2014). A quick look at Table A3 confirms that this problem also exists in our external dataset. With only three exceptions, none of the three tests was able to reject its respective null hypothesis at the $10 \%$ significance level.

However, we subscribe to the view that inflation rates generally achieved low and fairly stable levels in most EU countries and can thus be assumed stationary (Forster and Tillman, 2014). Visual inspection generally does not cast doubt over stationarity in our inflation series, with the exception of several Central and Eastern European countries (CEECs), which were still undergoing disinflation processes in 2000s or did not have their inflation firmly stabilised at reasonable levels. ${ }^{3}$ We have thus created a sub-category for these countries under the name "East" and performed panel unit root tests. As shown in Table A4, the Im-Pesaran-Shin (IPS) and Levin-Lin-Chu (LLC) tests applied to national data reject the null hypothesis of unit root in all series, while the Breitung test only marginally rejects it in the "West" group (i.e. full sample with excluded "East" group), at 10\% significance level. Visual inspection and some doubts coming from the Breitung test thus lead us to first-difference inflation series for countries belonging to "East" prior to normalisation and further processing.

The ADF and KPSS test results applied to Poland's regional series are shown in Table A5. Surprisingly, the inconclusiveness of the results is at least as stark as in the case of the external dataset. Indeed, in none of the regions, the null hypotheses of unit root or non-unit root could be rejected so again we need to take further steps in order to make some inference on this issue. First, we observe boundaries of regional inflation rates in Figure 1 and conclude that they appear stationary because, unlike in most other CEECs, the disinflation process in Poland, triggered by a transition shock, was (admittedly narrowly) completed by the last quarter of 2001 when our sample begins. Moreover, we then apply the Elliot-Jansson test (Elliot, Jansson, 2003) - an extension of the covariate augmented Dickey-Fuller (CADF) test

\footnotetext{
${ }^{3}$ This group consists of Bulgaria, Hungary, Estonia, Latvia, Lithuania, Romania, Slovakia and Slovenia. Line graphs of national inflation rates have not been presented here to save space. Data (and graphs) are readily available in the Eurostat database.
} 
by Hansen (1995) - which employs information from a stationary covariate to gain additional power. To perform this test, we need a stationary covariate (or several covariates), which can explain some part of movements in the tested variable, i.e. produce a reasonably high $\mathrm{R}^{2}$. The latter translates into the power gain over the $\mathrm{ADF}$ test.

Since regional inflation rates seem to move quite closely together and together with the national average, we now use the national unemployment rate as a common stationary covariate for all inflation series. The last column in Table A5 shows that with the additional power, the test now rejects the unit root in nearly all cases. Out of only three regions where the unit root hypothesis is not rejected at $5 \%$ level of significance, Lubelskie is not far away from the critical value, while Świętokrzyskie appears to be the border case. Finally, all the panel unit root test results presented in Table A6 strongly reject the null hypothesis of nonstationarity. We believe that there is enough evidence to treat regional inflation rates as stationary processes in the remainder of the paper.

\section{Empirical model}

Our empirical strategy to decompose shocks in regional inflation in Poland relies on the approaches of Forni and Reichlin (2001) and Beck et al. (2009). Let $\hat{\pi}_{j t}$ denote consumer price inflation rate in $\mathrm{j}$-th region, which is driven by global, national and local shocks:

$\hat{\pi}_{j t}=a_{j} \hat{g}_{t}+b_{j} \hat{k}_{t}+e_{j t}$

$j=1, \ldots, 16$.

$a_{j}$ and $b_{j}$ are functions capturing global $\left(\hat{g}_{t}\right)$ and national $\left(\hat{k}_{t}\right)$ shocks to $\mathrm{j}$-th region inflation, respectively. Region-specific idiosyncratic shock is captured by $e_{j t}$.

None of the shocks in equation (1) are observable. Moreover, all of them are very complex processes, which could perhaps be described with the help of a large number of economic variables. Our approach is to identify common dynamics in a large number of series and capture it with a small number of estimated components. As mentioned earlier, we assume that external (global and national) shocks are already embedded in respective inflation rates (i.e. global demand conditions first determine inflation rates in EU countries, rather than directly affecting inflation rates in Polish individual regions). In this way, we address the potential time lag issue between economic variables (impulses) and inflation (responses), 
while also hedging against an excessive number of components, which would need to be extracted to capture multidimensional global economic dynamics adequately. ${ }^{4}$ Avoiding large number of components and a developed dynamic specification is a necessity in any case, given our short time series.

Prior to estimation, series are normalised to zero mean and unit variance in order to make the estimation of components invariant to scale. We divide our normalised data set into a global and national block and use them separately to estimate the components as proxies of $\hat{g}_{t}$ and $\hat{k}_{t}$. The components will fill the shock-proxy vectors $g_{t}$ and $k_{t}$, respectively:

$\pi_{j t}=\lambda_{j}^{g} g_{t}+\lambda_{j}^{k} k_{t}+u_{j t}$

Where $\pi_{j t}$ is the normalised inflation rate. The disturbance term $u_{j t}$, assumed to be at most weakly dependent and stationary, is a proxy for an idiosyncratic shock. $\lambda_{j}$ are vectors of region-specific loadings associated with the global and national components.

Being that we are only interested in the sources of shocks, no restrictions to identifying elements of $g_{t}$ and $k_{t}$ as demand or supply shocks are imposed. However, identification of the model requires that they be pairwise orthogonal (Stock and Watson, 2002). We follow a strategy similar to that of Beck et al. (2009) to conform to this orthogonality assumption. First, we extract K-first principal components from our global series block (i.e. we create the $g_{t}$ vector). Second, we clean regional series by regressing each of them on the global components. Residuals are then collected and used to estimate national components.

There are several approaches to guide a researcher in choosing an optimal number of components or factors to be retained. ${ }^{5}$ The most common approaches are either to impose a desired share of variance to be explained, or to rely on inspecting the screeplot of eigenvalues and/or use the Kaiser rule, in which components are truncated when the eigenvalue falls below unity. Let $V_{n}>0$ denote eigenvalue of n-th principal component. The Kaiser rule thus boils down to applying the following retention criterion (see: Dinno, 2014):

\footnotetext{
${ }^{4}$ Such an empirical exercise was performed and indeed led to the necessity of extracting at least 4-5 components to capture developments in both external environment and Poland. In addition, models based on inflation series appear to be much better fitted to data.

5 see Breitung and Eickmeier (2005) for a detailed discussion.
} 


$$
V_{n} \begin{cases}>1 & \text { retain } \\ \leq 1 & \text { do not retain }\end{cases}
$$

One problem here is that the eigenvalues are prone to a sample bias and the Kaiser criterion is only appropriate at an infinite sample size (Hayton, et al., 2004; Dinno, 2009). Thus, we have implemented the Horn's parallel analysis (PA, Horn, 1965), which corrects the Kaiser rule's eigenvalues with the help of a Monte Carlo procedure. First, a matrix of independent and normally distributed variables are generated, respecting the original dimensions of the data matrix. Second, principal components are extracted from a correlation matrix of the data matrix generated in step one. Both steps are repeated 1000 times, while the PA eigenvalues $\left(V_{n}^{P A}>0\right)$ are averaged to obtain $\overline{V_{n}^{P A}}$. Finally, adjusted eigenvalues are calculated:

$V_{n}^{a d j}=V_{n}-\left(\overline{V_{n}^{P A}}-1\right)$

Adjusted eigenvalues are then plugged to equation (3):

$$
V_{n}^{a d j} \begin{cases}>1 & \text { retain } \\ \leq 1 & \text { do not retain }\end{cases}
$$

The adjusted eigenvalues have been corrected for sampling error that may result from small samples (Peres-Neto et al., 2005). In the recent simulation studies concerning robustness of various component and factor retention techniques performed by Ruscio and Roche (2012) and Courtney (2013), the Horn's PA tends to stand out as the preferred method.

In the last stage, variance decomposition has been performed to calculate the proportions of variance explained by external, national and idiosyncratic shocks. Our approach guarantees that:

$$
\operatorname{var}\left(\pi_{j t}\right)=\operatorname{var}\left(\lambda_{j}^{g} g_{t}\right)+\operatorname{var}\left(\lambda_{j}^{k} k_{t}\right)+\operatorname{var}\left(u_{j t}\right)
$$

\section{Results}

We now turn to the estimation of global shocks from our external inflation database. Initial candidates have been extracted with the principal component method from our complete external inflation database. The Horn's adjusted eigenvalues suggest that three components 
should be retained; therefore, we run the Kaiser-Meyer-Olkin (KMO, Kaiser, 1974) sampling adequacy test and check communalities, i.e. the proportion of explained variance with the three initial components, in order to track the items that do not fit our sample. After eliminating items with communalities below $0.50^{6}$ (series for Norway, Hungary and Slovakia in our case), we arrive at a final dataset, re-run the principal component analysis and retain the final three components, as advised by the Horn's adjusted eigenvalues (Table 1).

Table 1. Horn's eigenvalues and proportion of variance explained by first global components

\begin{tabular}{r|rrr}
\hline & $\begin{array}{r}\text { Adjusted } \\
\text { Eigenvalue }\end{array}$ & Proportion & $\begin{array}{r}\text { Cumulative } \\
\text { proportion }\end{array}$ \\
\hline $\mathbf{1}$ & $\mathbf{1 0 . 8 2 6}$ & $\mathbf{0 . 4 6 0}$ & $\mathbf{0 . 4 6 0}$ \\
$\mathbf{2}$ & $\mathbf{4 . 0 0 2}$ & $\mathbf{0 . 1 9 7}$ & $\mathbf{0 . 6 5 7}$ \\
$\mathbf{3}$ & $\mathbf{1 . 9 8 3}$ & $\mathbf{0 . 1 2 0}$ & $\mathbf{0 . 7 7 7}$ \\
4 & 0.586 & 0.062 & 0.838 \\
5 & 0.262 & 0.044 & 0.882 \\
\hline
\end{tabular}

Notes: Sample after excluding Norway due to insufficient communality (below .50) and very low Kaiser-MeyerOlkin measure (.28). Excluding Norway, improved cumulative proportion of variance explained by three first principal components from .767 to .780 , but did not influence the number of retained factors.

The total KMO measure of sampling adequacy is 0.65 , which is acceptable (although would be labeled 'mediocre' in the original interpretation of Kaiser, 1974), while the mean communality is 0.88 , which is high and thus fully satisfactory. The three global components jointly explain $77.7 \%$ of the variance in our external inflation dataset. ${ }^{7}$ While we do not formally identify components, it is clear that the first one mostly captures inflation developments in "old" EU member states, while the second one is related to its dynamics in Central and Eastern European countries (except Romania) and the third one might possibly be associated with the UK and Romania.

As mentioned in the previous section, global components are subsequently regressed on individual regional inflation series, while residuals are collected to extract national components. These estimation results are presented in Table 2 and already permit some interesting insights. The national component as well as first and third global components turn out to be highly significant in driving regional inflation in Poland. The second global component (we have associated it with CEECs) appears significant in only four regions. This finding does not allow us to claim that inflation in peer Central and Eastern European countries is irrelevant. Instead, a more subtle interpretation seems appropriate. Due to the fact

\footnotetext{
${ }^{6} 0.50$ is the frequently used minimum communality criterion in principal component analysis (see: Larose, 2006, p. 16).

${ }^{7} \mathrm{KMO}$ measures and factor loadings are not presented to save space, but they are available upon request.
} 
that this component is loaded with first-differenced data, we may conclude that an acceleration or deceleration in inflation there did not turn significant as inflation determinant in most Polish regions.

Table 2. Estimation results - dependent variable: regional inflation rates

\begin{tabular}{l|rcrrr}
\hline & Global 1 & Global 2 & Global 3 & National 1 & $R^{2}$ \\
\hline DOL & $0.142 * * *$ & -0.014 & $0.197 * * *$ & $0.201 * * *$ & 0.981 \\
KPM & $0.135 * * *$ & 0.011 & $0.226 * * *$ & $0.198 * * *$ & 0.981 \\
LBL & $0.151 * * *$ & 0.009 & $0.169 * * *$ & $0.200 * * *$ & 0.978 \\
LUB & $0.134 * * *$ & -0.001 & $0.157 * * *$ & $0.211 * * *$ & 0.971 \\
MAZ & $0.153 * * *$ & $-0.044 * * *$ & $0.125 * * *$ & $0.205 * * *$ & 0.983 \\
MLP & $0.137 * * *$ & 0.002 & $0.143 * * *$ & $0.214 * * *$ & 0.991 \\
OPO & $0.137 * * *$ & -0.014 & $0.179 * * *$ & $0.207 * * *$ & 0.979 \\
PDK & $0.120 * * *$ & 0.005 & $0.175 * * *$ & $0.216 * * *$ & 0.986 \\
PDL & $0.134 * * *$ & $0.015 * *$ & $0.135 * * *$ & $0.217 * * *$ & 0.988 \\
POM & $0.114 * * *$ & $0.038 * * *$ & $0.155 * * *$ & $0.216 * * *$ & 0.971 \\
WMZ & $0.113 * * *$ & $0.027 * * *$ & $0.223 * * *$ & $0.209 * * *$ & 0.985 \\
WLK & $0.133 * * *$ & 0.002 & $0.189 * * *$ & $0.208 * * *$ & 0.988 \\
ZPM & $0.142 * * *$ & -0.014 & $0.197 * * *$ & $0.201 * * *$ & 0.981 \\
SLA & $0.135 * * *$ & 0.011 & $0.226 * * *$ & $0.198 * * *$ & 0.981 \\
SWK & $0.151 * * *$ & 0.009 & $0.169 * * *$ & $0.200 * * *$ & 0.978 \\
LDZ & $0.134 * * *$ & -0.001 & $0.157 * * *$ & $0.211 * * *$ & 0.971 \\
\hline
\end{tabular}

Notes: $* * * * *, *$ denote significance at $1 \%, 5 \%$ and $10 \%$, respectively.

In order to obtain national components, we followed the same retention algorithm, although there is no need to reiterate it being that all regional series exhibit, as to be expected, very high communality and the full sample KMO measure hits 0.93 , which corresponds to the interpretive adjective 'marvelous' according to Kaiser (1974). The Horn's PA analysis leaves no doubt over how many components should be kept. The first one explains more than $97 \%$ of the remaining variance in regional inflation rates (Table 3). Component loadings are presented in Table 4.

Table 3. Horn's eigenvalues and proportion of variance explained by first national components

\begin{tabular}{r|rrr}
\hline & Adjusted & & $\begin{array}{c}\text { Cumulative } \\
\text { Component }\end{array}$ \\
Eigenvalue & Proportion & proportion \\
\hline $\mathbf{1}$ & $\mathbf{1 4 . 3 7 3}$ & $\mathbf{0 . 9 7 5 7}$ & $\mathbf{0 . 9 7 5 7}$ \\
2 & 0.07 & 0.0052 & 0.9809 \\
\hline
\end{tabular}


Table 4. Component loadings on retained national component

\begin{tabular}{c|ccc}
\hline & Component & Unexplained & KMO \\
\hline DOL & 0.2495 & 0.0284 & 0.8898 \\
KPM & 0.2495 & 0.0285 & 0.9521 \\
LBL & 0.2491 & 0.0315 & 0.9667 \\
LUB & 0.2481 & 0.0390 & 0.9339 \\
MAZ & 0.2502 & 0.0225 & 0.9096 \\
MLP & 0.2517 & 0.0107 & 0.9494 \\
OPO & 0.2495 & 0.0284 & 0.9601 \\
PDK & 0.2508 & 0.0182 & 0.9499 \\
PDL & 0.2512 & 0.0152 & 0.8804 \\
POM & 0.2484 & 0.0365 & 0.8764 \\
WMZ & 0.2504 & 0.0213 & 0.9571 \\
WLK & 0.2511 & 0.0160 & 0.9006 \\
ZPM & 0.2499 & 0.0249 & 0.9584 \\
SLA & 0.2500 & 0.0244 & 0.9546 \\
SWK & 0.2502 & 0.0225 & 0.9334 \\
LDZ & 0.2504 & 0.0212 & 0.8975 \\
\hline & & $\mathbf{0 . 0 2 4 3} *$ & $\mathbf{0 . 9 2 8 3} * *$ \\
\hline
\end{tabular}

Notes: KMO: Kaiser-Meyer-Olkin measure of sampling adequacy. * Mean; ** Total.

Our analysis produces three sets of pairwise orthogonal components, which can now be used to calculate variance decomposition of regional inflation rates. The results are presented in Table 5. Several important results emerge. First, the importance of idiosyncratic shocks in the Polish regions is strikingly low; indeed, they explain between $0.7 \%$ and $2.8 \%$ of total regional inflation variance. The average contribution $(1.6 \%)$ is thus much lower than in the regions investigated by Beck et al. (2009), only coming close to the Finnish case (2.8\%) in their study. More differences in inflation co-movements across Polish regions might potentially source from the relative importance of global and national shocks. The share of global component in explaining inflation variance ranges from $24.7 \%$ to $38.3 \%$ and the national one explains between $59.9 \%$ and $72.6 \%$, which leaves some potential to generate cross-regional divergence. 
Table 5. Share of variance explained by global, national and region-specific shocks

\begin{tabular}{c|rrr}
\hline & Global & National & $\begin{array}{r}\text { Region- } \\
\text { specific }\end{array}$ \\
\hline DOL & 0.368 & 0.614 & 0.018 \\
KPM & 0.383 & 0.599 & 0.018 \\
LBL & 0.368 & 0.612 & 0.020 \\
LUB & 0.294 & 0.679 & 0.028 \\
MAZ & 0.345 & 0.640 & 0.015 \\
MLP & 0.293 & 0.699 & 0.008 \\
OPO & 0.329 & 0.652 & 0.019 \\
PDK & 0.273 & 0.713 & 0.013 \\
PDL & 0.277 & 0.712 & 0.011 \\
POM & 0.247 & 0.726 & 0.027 \\
WMZ & 0.317 & 0.668 & 0.015 \\
WLK & 0.327 & 0.662 & 0.011 \\
ZPM & 0.347 & 0.637 & 0.016 \\
SLA & 0.379 & 0.606 & 0.015 \\
SWK & 0.349 & 0.636 & 0.015 \\
LDZ & 0.299 & 0.687 & 0.015 \\
\hline Average & 0.325 & 0.659 & 0.016 \\
\hline
\end{tabular}

These results lead us to formulate the second ad-hoc hypothesis:

$\mathrm{H}_{2}$ : Shocks to inflation, which are asymmetric between Poland and its external environment, contribute to cross-regional divergence of inflation rates in Poland.

It is instructive to observe in Figure 2 how regional inflation rates in Poland diverged when the crisis struck in late 2008. EU faced a rapid deterioration in demand conditions, which was immediately reflected in disinflation, while in Poland the shock was initially absorbed by exchange rate depreciation. The growing inflation gap between EU and Poland between 2008Q4 and 2009Q3 was indeed accompanied by divergence in cross-regional inflation. This divergence was subsequently reversed when the inflation gap narrowed again in the course of late 2009 and early 2010 (see also Figure 1). 
Figure 2. Disparity between inflation rates in Poland and EU and inflation differences across Polish regions, 2008Q1-2010Q2.

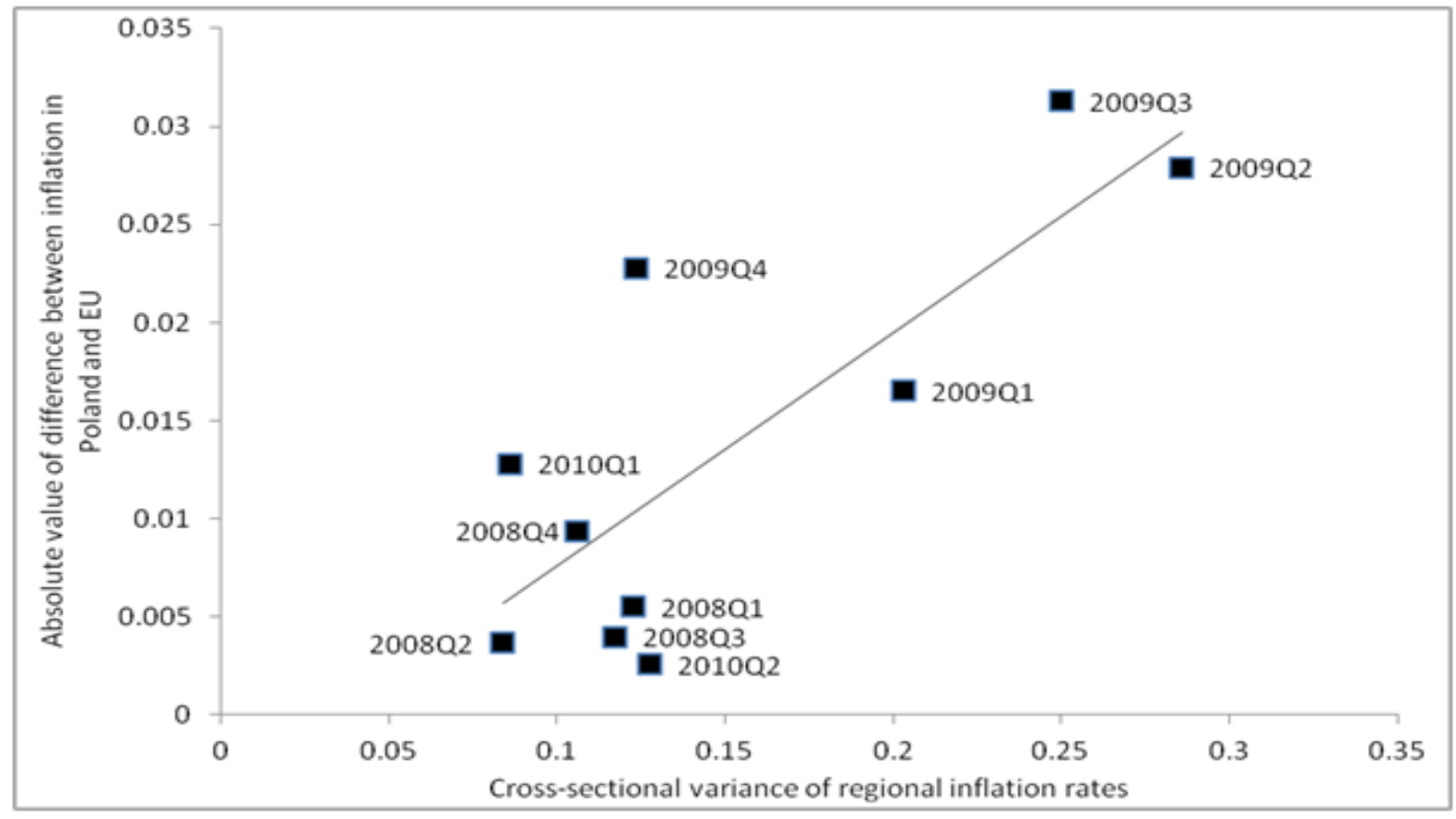

We will now perform a formal test of $\mathrm{H}_{2}$ and check the relationship between the crossregional dispersion of inflation rates (measured with variance) and the deviation between EU and Poland's aggregate CPI inflation by estimating the parameters of the following equation:

$\operatorname{var}\left(\pi_{i}\right)_{t}=\alpha_{0}+\alpha_{1}\left|\pi_{E U, t}-\pi_{P L, t}\right|+\eta_{t}$

The estimation results are presented in column (1) of Table 6. While they suggest a positive impact of the EU-Poland inflation differential on cross-regional inflation divergence, the overall model fit and quality are not satisfactory. Even though the Prais-Winsten method was employed to accommodate serial correlation, the model still suffers from some problems, including the omitted variable bias indicated by the Ramsey's RESET test. In an attempt to correct the model, we decided to make use of the observation that cross-regional inflation dispersion might respond to stronger asymmetric shocks and introduce the squared term in equation 7.

The results in column (2) of Table 6 suggests significant improvement of the model fit. Moreover, the Ramsey's RESET test no longer rejects the null hypothesis of "no omitted variables" and the heteroskedasticity problem seems also to be eliminated. We also control whether residuals follow the normal distribution and find no major issues here (see Table A7). 
Squared inflation difference thus appears highly significant and so the results support our second ad-hoc hypothesis.

Table 6. Estimation results of equation 7

\begin{tabular}{l|cc}
\hline & $(1)$ & $(2)$ \\
\hline Inflation difference & $0.024 * *$ & -0.0327 \\
& $(0.010)$ & $(0.024)$ \\
Inflation difference) $^{2}$ & & $2.320^{* * *}$ \\
& & $(0.871)$ \\
Intercept & $0.001 * * *$ & $0.001^{* * *}$ \\
& $(0.000)$ & $(0.000)$ \\
\hline $\mathrm{R}^{2}$ & 0.081 & 0.192 \\
D-W (original) & 0.706 & 0.787 \\
D-W (transformed) & 1.724 & 1.842 \\
Breusch-Pagan test for heteroscedasticity & 0.047 & 0.923 \\
$(p-v a l)$ & & \\
Ramsey's RESET test for omitted & 0.013 & 0.363 \\
variables ( $p$-val) & & \\
Normality of residuals Chi ${ }^{2}(p$-val) & 0.127 & 0.117 \\
\hline
\end{tabular}

Notes: $* * * * * *$ indicate significance at $1 \%$ and $5 \%$, respectively. Estimations performed with the Prais-Winsten method to correct for serial correlation. Standard errors in parentheses.

There is little doubt that the dispersion of cross-regional inflation in Poland is also affected by nominal exchange rate movements. Indeed, all external shocks are transmitted via the exchange rate and ultimately reveal themselves in terms of trade. We have made several attempts to use import and export price differentials as regressors to explain cross-regional inflation dispersion, but these attempts did not turn out to be successful. ${ }^{8}$ One possible explanation is that the exchange rate can both absorb asymmetric inflation shocks and aggravate them due to overshooting. Indeed, it was not infrequent to observe that shocks to economic activity triggered violent capital flows between Poland and other European countries which, in turn, have increased exchange rate volatility. While it could have played an absorbing role in terms of the shock to economic activity, the impact upon inflation differentials and terms of trade was not unequivocal.

\footnotetext{
${ }^{8}$ Only some weak signs of positive impact of import prices were found. Results are available upon request.
} 


\section{Concluding remarks}

This article has investigated the role of global, national and idiosyncratic factors in explaining regional inflation across Polish regions. Its main finding is that while idiosyncratic shocks explain a minor share in total variance, some differences exist in the proportion split between global and national components. Comparing our results to those of Beck et al. (2009) we could argue that if Poland joins the EMU, regional inflation patterns may change insofar as the national component may lose some of its significance to the global component. At the same time, there is no reason to expect that the role of idiosyncratic component will be altered, i.e. it should remain small. While it is not certain what proportion of the national component will be "transferred" to the global one, the small idiosyncratic component is favourable from the perspective of adopting the euro in Poland.

The dispersion in the composition of external and national shocks is apparently not strong enough to substantially weaken co-movements between cross-regional inflation rates in normal times, whereas in the presence of shocks exerting an asymmetric impact on Poland and other countries, cross-regional inflation divergence within Poland can escalate, especially when this asymmetry is strong.

An important question, and one which remains open, is about region-specific factors driving the composition of shocks affecting inflation. At a first glance, there does not seem to be any relationship between the importance of global and national shocks, on the one hand, and income, industry mix, trade intensity or geographical location on the other. Due to the insufficient number of regions in our sample required to perform cross-sectional regressions, this question has not been addressed and this problem should therefore be subject to further investigations.

\section{References}

1. Alberola, E. \& Marqués, J. M. (1999) On the Relevance and Nature of Regional Inflation Differentials: the Case of Spain, Banco de Espana Working Papers 9913, Banco de Espana.

2. Beck, G. Hubrich, K. \& Marcellino, M. (2009) Regional inflation dynamics within and across euro area countries and a comparison with the United States, Economic Policy, 24, pp. 141-184.

3. Breitung, S., \& Eickmeier, J. (2005) Dynamic factor models, Deutsche Bundesbank Discussion Paper Series 1: Economic Studies, no. 38/2005.

4. Chang, T., Ranjbar, O. \& Tang, D.P. (2013) Revisiting the mean reversion of inflation rates for 22 OECD countries, Economic Modelling, 30, pp. 245-252. 
5. Ciccarelli, M. \& Mojon, B. (2010) Global Inflation, The Review of Economics and Statistics, 92, pp. 524-535.

6. Courtney, M. G. R. (2013) Determining the number of factors to retain in EFA: Using the SPSS R-Menu v2.0 to make more judicious estimations, Practical Assessment, Research and Evaluation, 18, pp. 1-14.

7. Dąbrowski, M.A. \& Wróblewska, J. (2015) Has exchange rate flexibility of the Polish zloty been conducive to shock absorption? The $9^{\text {th }}$ Professor Aleksander Zelias International Conference on Modelling and Forecasting of Socio-Economic Phenomena.

8. Dinno, A. (2009) Implementing Horn's parallel analysis for principal component analysis and factor analysis, The Stata Journal, 9, pp. 291-298.

9. Dinno, A. (2014) Gently Clarifying the Application of Horn's Parallel Analysis to Principal Component Analysis versus Factor Analysis, mimeo.

10. Eickmeier, S. \& Moll, K. (2009) The global dimension of inflation - evidence from factor-augmented Phillips curves, ECB Working Paper Series, 1011, European Central Bank.

11. Elliott, G. \& Jansson, M. (2003) Testing for unit roots with stationary covariates, Journal of econometrics, Journal of Econometrics, 115, pp. $75-89$.

12. Forni, M. \& Reichlin, L. (2001) Federal policies and local economies: Europe and the US, European Economic Review, 45, pp. 109-134.

13. Forster, M. \& Tillmann, P. (2014) Reconsidering the International Comovement of Inflation, Open Economies Review, 25, pp. 841-863.

14. García-Cintado, A. C., Romero-Ávila, D. \& Usabiaga, C. (2015) A PANIC analysis on regional \& sectoral inflation: the Spanish case, Applied Economics, 47, pp. 4685-4713, DOI: $10.1080 / 00036846.2015 .1034838$

15. Hałka, A. \& Szafrański, G. (2015) What common factors are driving inflation in CEE countries? NBP Working Paper, no. 225.

16. Hansen, B.E. (1995) Rethinking the univariate approach to unit root testing: using covariates to increase power, Econometric Theory, 11, pp. 1148-1171.

17. Hayton, J.C., Allen, D.G. \& Scarpello, V. (2004) Factor retention decisions in exploratory factor analysis: a tutorial on parallel analysis, Organisational Research Methods, 7, pp. 191-205.

18. Horn, J. L. (1965) A rationale and test for the number of factors in factor analysis. Psychometrika, 30, 179-185.

19. Kaiser, H. F. (1974) An index of factor simplicity, Psychometrika, 39, pp. 31-36.

20. Krajewski, P., Mackiewicz, M. \& Piłat, K. (2015) The optimal fiscal rule in the context of accession to the Eurozone, Economic Research - Ekonomska Istrazivanja, 28, pp. 398406.

21. Krusper, B. (2012) The role of external \& country specific factors in Hungarian inflation developments, MNB Working Papers, 5/2012.

22. Larose, D.T. (2006) Data Mining Methods \& Models, John Wiley \& Sons, Hoboken, New Jersey.

23. Mehrotra, A., Peltonen, T. \& Santos Rivera, A. (2007) Modelling inflation in China - a regional perspective, Bank of Finland, Institute for Economics in Transition, Discussion Papers, no. 18.

24. Monacelli, T. \& Sala, L. (2009) The international dimension of inflation: evidence from disaggregated consumer price data, Journal of Money, Credit and Banking, 41 pp. 101-120.

25. Marques H., Pino G. \& Horrillo, J. D. T. (2014) Regional inflation dynamics using space-time models, Empirical Economics, 47, pp. 1147-1172, DOI 10.1007/s00181-0130763-9. 
26. Mumtaz, H. \& Surico, P. (2012) Evolving international inflation dynamics: world \& country-specific factors, Journal of the European Economic Association, 10, pp. 716734.

27. Nagayasu, J. (2011) Heterogeneity and convergence of regional inflation (prices), Journal of Macroeconomics, 33, pp. 711-723.

28. Peres-Neto, P.R., Jackson, D.A. \& Somers, K.M. (2005) How many principal components? Stopping rules for determining the number of non-trivial axes revisited. Computational Statistics and Data Analysis, 49, pp. 974-997.

29. Romero-Ávila, D. \& Usabiaga, C. (2012) Disaggregate evidence on Spanish inflation persistence, Applied Economics, 44, pp. 3029-3046, DOI: 10.1080/00036846.2011.568412

30. Ruscio, J. \& Roche, B. (2012) Determining the number of factors to retain in an exploratory factor analysis using comparison data of known factorial structure. Psychological Assessment, 24, pp. 282-292.

31. Stavrev, E. (2009) Forces driving inflation in the new EU10 members, IMF Working Papers, 09/51.

32. Stock, J.H. \& Watson, M.W. (2002) Forecasting using principal components from a large number of predictors, Journal of the American Statistical Association, 97, pp. 1167-1179.

33. Vaona, A. \& Ascari, G. (2012) Regional inflation persistence: evidence from Italy, Regional Studies, 46, pp. 509-523.

34. Yilmazkuday, H. (2013) Inflation targeting, flexible exchange rates and inflation convergence, Applied Economics, 45, pp. 593-603. 
Tables - Appendix

Table A1. Descriptive statistics

\begin{tabular}{|c|c|c|c|c|c|c|}
\hline & $\begin{array}{c}\text { Variable } \\
\text { name }\end{array}$ & Obs & Mean & S.D. & Min & Max \\
\hline \multicolumn{7}{|c|}{ NUTS2 regions in Poland } \\
\hline Dolnośląskie & DOL & 55 & 2.52 & 1.76 & -1.29 & 5.40 \\
\hline Kujawsko-pomorskie & KPM & 55 & 2.24 & 1.74 & -1.39 & 5.07 \\
\hline Lubelskie & LBL & 55 & 2.14 & 1.71 & -1.69 & 4.87 \\
\hline Łódzkie & LDZ & 55 & 2.33 & 1.53 & -0.50 & 4.67 \\
\hline Lubuskie & LUB & 55 & 2.48 & 1.52 & -1.00 & 4.88 \\
\hline Mazowieckie & MAZ & 55 & 2.31 & 1.77 & -1.89 & 4.88 \\
\hline Małopolskie & MLP & 55 & 2.38 & 1.68 & -1.59 & 4.88 \\
\hline Opolskie & $\mathrm{OPO}$ & 55 & 2.24 & 1.48 & -1.39 & 4.47 \\
\hline Podkarpackie & PDK & 55 & 2.32 & 1.77 & -1.79 & 5.19 \\
\hline Podlaskie & PDL & 55 & 2.53 & 1.78 & -1.59 & 5.40 \\
\hline Pomorskie & POM & 55 & 2.19 & 1.76 & -2.08 & 4.87 \\
\hline Śląskie & SLA & 55 & 2.28 & 1.80 & -1.20 & 5.29 \\
\hline Świętokrzyskie & SWK & 55 & 2.44 & 1.76 & -1.59 & 5.40 \\
\hline Wielkopolskie & WLK & 55 & 2.12 & 1.60 & -1.79 & 4.67 \\
\hline Warmińsko-mazurskie & wMZ & 55 & 2.09 & 1.52 & -1.29 & 4.57 \\
\hline Zachodniopomorskie & $\mathrm{ZPM}$ & 55 & 2.36 & 1.96 & -2.28 & 5.29 \\
\hline \multicolumn{7}{|c|}{ Countries } \\
\hline & & Obs & Mean & S.D. & Min & Max \\
\hline Austria & $\mathrm{AT}$ & 55 & 2.01 & 0.70 & 0.43 & 3.53 \\
\hline Belgium & $\mathrm{BE}$ & 55 & 2.04 & 1.01 & -0.13 & 4.50 \\
\hline Bulgaria & BG & 55 & 4.61 & 3.43 & -1.67 & 12.47 \\
\hline Cyprus & $\mathrm{CY}$ & 55 & 2.21 & 1.26 & -0.43 & 4.50 \\
\hline Czech Republic & $\mathrm{CZ}$ & 55 & 2.17 & 1.56 & -0.20 & 6.43 \\
\hline Germany & DE & 55 & 1.65 & 0.66 & 0.20 & 3.07 \\
\hline Denmark & DK & 55 & 1.82 & 0.81 & 0.20 & 3.60 \\
\hline Estonia & $\mathrm{EE}$ & 55 & 3.94 & 2.49 & -0.53 & 10.77 \\
\hline Spain & ES & 55 & 2.50 & 1.25 & -0.60 & 4.37 \\
\hline Finland & FI & 55 & 1.91 & 0.98 & 0.07 & 3.80 \\
\hline France & FR & 55 & 1.76 & 0.70 & 0.13 & 3.30 \\
\hline Greece & GR & 55 & 2.55 & 1.79 & -1.60 & 4.97 \\
\hline Croatia & $\mathrm{HR}$ & 55 & 2.66 & 1.32 & 0.10 & 5.93 \\
\hline Hungary & $\mathrm{HU}$ & 55 & 4.77 & 2.21 & -0.27 & 10.07 \\
\hline Iceland & IC & 55 & 5.49 & 4.39 & 0.40 & 18.13 \\
\hline Ireland & $\mathrm{IE}$ & 55 & 1.89 & 1.89 & -2.50 & 4.70 \\
\hline Italy & IT & 55 & 2.14 & 0.86 & 0.00 & 3.57 \\
\hline Lithuania & LT & 55 & 2.81 & 2.97 & -1.03 & 11.07 \\
\hline Luxembourg & $\mathrm{LU}$ & 55 & 2.54 & 1.06 & -0.07 & 4.37 \\
\hline Latvia & LV & 55 & 4.40 & 4.22 & -1.90 & 15.57 \\
\hline Malta & MT & 55 & 2.27 & 0.98 & 0.50 & 4.60 \\
\hline Netherlands & $\mathrm{NL}$ & 55 & 2.08 & 1.17 & 0.07 & 5.07 \\
\hline Norway & NO & 55 & 1.73 & 0.80 & 0.33 & 3.40 \\
\hline Portugal & PT & 55 & 2.21 & 1.41 & -0.87 & 4.40 \\
\hline Romania & RO & 55 & 9.76 & 8.69 & 1.07 & 38.30 \\
\hline Sweden & $\mathrm{SE}$ & 55 & 1.57 & 0.80 & 0.20 & 3.37 \\
\hline Slovakia & SK & 55 & 3.57 & 2.41 & -0.20 & 8.63 \\
\hline Slovenia & SL & 55 & 3.53 & 2.33 & -0.17 & 9.07 \\
\hline United Kingdom & UK & 55 & 2.30 & 0.93 & 0.77 & 4.40 \\
\hline United States & US & 55 & 2.27 & 1.24 & -1.10 & 4.77 \\
\hline
\end{tabular}

Notes: Test for equality of means in regional series $\left(\mathrm{H}_{0}\right.$ : equal regional mean inflation rates): $\mathrm{F}(15,40)=26.23, \mathrm{p}(\mathrm{val})=0.00$. 
Table A2. Pairwise correlation coefficients between regional inflation rates

\begin{tabular}{|c|c|c|c|c|c|c|c|c|c|c|c|c|c|c|c|c|}
\hline & $D O L$ & $K P M$ & $L B L$ & $L D Z$ & $L U B$ & $M A Z$ & $M L P$ & $O P O$ & $P D K$ & $P D L$ & $P O M$ & $S L A$ & $S W K$ & $W L K$ & $W M Z$ & $Z P M$ \\
\hline DOL & 1.00 & & & & & & & & & & & & & & & \\
\hline KPM & 0.98 & 1.00 & & & & & & & & & & & & & & \\
\hline LBL & 0.97 & 0.97 & 1.00 & & & & & & & & & & & & & \\
\hline LDZ & 0.98 & 0.98 & 0.97 & 1.00 & & & & & & & & & & & & \\
\hline LUB & 0.97 & 0.97 & 0.97 & 0.97 & 1.00 & & & & & & & & & & & \\
\hline MAZ & 0.97 & 0.96 & 0.97 & 0.97 & 0.96 & 1.00 & & & & & & & & & & \\
\hline MLP & 0.99 & 0.97 & 0.98 & 0.99 & 0.98 & 0.98 & 1.00 & & & & & & & & & \\
\hline $\mathrm{OPO}$ & 0.99 & 0.97 & 0.97 & 0.98 & 0.97 & 0.97 & 0.99 & 1.00 & & & & & & & & \\
\hline PDK & 0.98 & 0.97 & 0.97 & 0.98 & 0.97 & 0.97 & 0.99 & 0.98 & 1.00 & & & & & & & \\
\hline PDL & 0.97 & 0.97 & 0.98 & 0.98 & 0.97 & 0.98 & 0.99 & 0.97 & 0.98 & 1.00 & & & & & & \\
\hline POM & 0.95 & 0.96 & 0.96 & 0.97 & 0.96 & 0.96 & 0.97 & 0.97 & 0.97 & 0.97 & 1.00 & & & & & \\
\hline SLA & 0.99 & 0.97 & 0.97 & 0.97 & 0.97 & 0.97 & 0.98 & 0.98 & 0.97 & 0.97 & 0.94 & 1.00 & & & & \\
\hline SWK & 0.98 & 0.98 & 0.99 & 0.99 & 0.98 & 0.97 & 0.98 & 0.97 & 0.98 & 0.98 & 0.96 & 0.97 & 1.00 & & & \\
\hline WLK & 0.98 & 0.98 & 0.98 & 0.98 & 0.98 & 0.97 & 0.99 & 0.98 & 0.98 & 0.99 & 0.98 & 0.98 & 0.98 & 1.00 & & \\
\hline WMZ & 0.96 & 0.98 & 0.97 & 0.97 & 0.97 & 0.95 & 0.97 & 0.97 & 0.98 & 0.97 & 0.97 & 0.96 & 0.97 & 0.98 & 1.00 & \\
\hline ZPM & 0.98 & 0.98 & 0.98 & 0.98 & 0.98 & 0.96 & 0.98 & 0.98 & 0.98 & 0.97 & 0.96 & 0.98 & 0.98 & 0.98 & 0.98 & 1.00 \\
\hline
\end{tabular}

Table A3. Unit root test results - national inflation series

\begin{tabular}{c|cccccccccccccccccccccc}
\hline & $A T$ & $B E$ & $B G$ & $C Y$ & $C Z$ & $D E$ & $D K$ & $E E$ & $E S$ & $F I$ & $F R$ & $G R$ & $H R$ & $H U$ & $I C$ & -1.96 & -1.25 & -0.86 \\
\hline ADF & -1.47 & -1.40 & -0.92 & -0.80 & -1.71 & -0.95 & -0.80 & -1.08 & -0.23 & -1.05 & -0.97 & 0.62 & -1.46 \\
KPSS & 0.08 & 0.12 & 0.11 & 0.11 & 0.09 & 0.09 & 0.11 & 0.12 & 0.10 & 0.09 & 0.10 & 0.14 & 0.10 & 0.15 & 0.11 \\
PP & -2.53 & -2.51 & -1.66 & -1.88 & -2.56 & -2.18 & -1.85 & -2.19 & -1.43 & -1.91 & -2.14 & -0.45 & -2.39 & -1.92 & -1.76 \\
\hline & IE & IT & LT & LU & LV & MT & NL & NO & PT & RO & SE & SK & SL & UK & US \\
\hline ADF & -1.19 & -0.12 & -0.86 & -1.04 & -0.95 & -1.63 & -1.21 & -2.41 & -0.99 & -1.02 & -0.69 & -1.19 & -1.88 & -0.81 & -1.67 \\
KPSS & 0.08 & 0.09 & 0.18 & 0.11 & 0.17 & 0.13 & 0.12 & 0.08 & 0.07 & $0.43 *$ & 0.10 & 0.10 & 0.14 & 0.14 & 0.11 \\
PP & -1.69 & -1.53 & -1.71 & -2.17 & -1.80 & $-2.70 *$ & -1.73 & $-3.01 * *$ & -1.75 & -6.94 & -1.27 & -1.82 & -1.91 & -1.44 & -2.58 \\
\hline
\end{tabular}

Notes: $* * *$ denote significance at $5 \%$ and $10 \%$, respectively.

Table A4: Panel unit root test results - national data

\begin{tabular}{l|lcc}
\hline & $I P S$ & LLC & Breitung \\
\hline & \multicolumn{3}{|c}{ with constant term, without trend } \\
Full sample (31 countries) & $-15.923 * * *$ & $-15.233 * * *$ & 1.542 \\
West (23 countries) & $-14.401 * * *$ & $-12.841 * * *$ & $-1.334 *$ \\
East (8 countries) & $-8.586 * * *$ & $-7.146 * * *$ & 1.541
\end{tabular}

Notes: East group consists of: Bulgaria, Estonia, Lithuania, Latvia, Hungary, Romania, Slovakia and Slovenia. In all tests, the data was demeaned to address possible cross-section dependence. Lag lengths chosen by the BIC criterion. 
Table A5 Unit root test results - Polish regional series

\begin{tabular}{l|ccccc}
\hline & $A D F$ & \multicolumn{3}{c}{ Elliot-Jansson } \\
\hline & $5 \%$ crit value: -2.927 & $5 \%$ crit value: 0.463 & lambda & $5 \%$ crit value & $\mathrm{H}_{0}$ \\
DOL & -1.24 & 0.148 & 8.59 & 4.19 & + \\
KPM & -1.42 & 0.162 & 1.95 & 3.34 & - \\
LBL & -1.43 & 0.139 & 4.05 & 4.03 & + \\
LUB & -1.52 & 0.149 & -2.92 & 3.79 & - \\
MAZ & -1.15 & 0.142 & 0.66 & 3.71 & - \\
MLP & -1.43 & 0.14 & -5.69 & 4.02 & - \\
OPO & -1.37 & 0.146 & -0.11 & 3.81 & - \\
PDK & -1.25 & 0.139 & -7.65 & 4.74 & - \\
PDL & -1.58 & 0.137 & -3.92 & 3.45 & - \\
POM & -1.43 & 0.139 & -11.62 & 3.57 & - \\
WMZ & -1.28 & 0.159 & 0.77 & 7.96 & - \\
WLK & -1.29 & -4.44 & 5.05 & - \\
ZPM & -1.22 & 0.143 & 1.03 & 7.82 & - \\
SLA & -1.56 & 0.144 & 0.68 & 4.08 & + \\
SWK & -1.49 & 0.15 & 4.76 & 3.94 & - \\
LDZ & -1.34 & 0.157 & -0.33 & 3.58 & + \\
\hline
\end{tabular}

Notes: In the Elliot-Janssen test, the national unemployment rate was used as a stationary covariate. The ADF test rejected the unit root hypothesis in this series at $0.1 \%$ significance level. Maximum lag length set as 10 . Constant terms and no trend allowed in both the dependent variable and the covariate (i.e. case 3 in the nomenclature of Elliot and Jansson, 2003).

Table A6. Panel unit root test results applied to Polish regional inflation data

\begin{tabular}{l|lll}
\hline & IPS & LLC & Breitung \\
\hline & with constant term, without trend \\
Full sample (16 regions) & $-7.216 * * *$ & $-7.431 * * *$ & $-5.452 * * *$ \\
\hline
\end{tabular}

Notes: In all tests, data was demeaned to address possible cross-section dependence. Lag lengths chosen by the BIC criterion. 